\title{
Research history, taphonomy, and age structure of a mass accumulation of the ornithopod dinosaur Dysalotosaurus lettowvorbecki from the Upper Jurassic of Tanzania
}

Tom R. Hübner, Christian Foth, Wolf-Dieter Heinrich, Daniela Schwarz, and Robert Bussert Acta Palaeontologica Polonica 66 (2), 2021: 275-300 doi:https://doi.org/10.4202/app.00687.2019

The region around Tendaguru Hill in southeastern Tanzania has provided a rich, Late Jurassic dinosaur fauna. Among them, thousands of bones of the basal iguanodontian ornithopod Dysalotosaurus lettowvorbecki have been excavated in the Ig/WJ-quarry northwest of the Tendaguru Hill. The incomplete record of the taphonomic information from the excavation is the main reason for the still inconclusive interpretation of the assemblage as either catastrophic or attritional in origin. In this study, all available historical notes, sketches and field catalogues were analysed and combined with data from CT scans, new taphonomic observations and from bone histological as well as demographic analyses. According to these combined results, the mass accumulation of remains of $D$. lettowvorbecki consists of four closely associated bonebeds in at least three different stratigraphic levels. The bonebeds are classified as mixed, multitaxic, and monodominant. There is no evidence of abrasion and preburial weathering on the bones suggesting minimal transport distances and duration as well as short preburial exposure times. Although the size/age distributions are bimodally U-shaped, the bonebeds are interpreted as catastrophic in origin due to the restricted spatial extent and the overall uniform preservation of the bones. It is proposed that different herds of D. lettowvorbecki crossed a tidal channel several times during seasonal migration and that each time several to dozens of individuals died. The bodies decomposed and were buried at a barrier or a bend nearby. The demographic conditions as well as the modes of death and burial of D. lettowvorbecki are very similar to the observations made from the modern blue wildebeest in the Masai-Mara Reserve in Kenya.

Key words: Dinosauria, Dysalotosaurus lettowvorbecki , history, demography, taphonomy, Jurassic, Tendaguru, Africa.

Tom R. Hübner [ huebner@stiftung-friedenstein.de], Stiftung Schloss

Friedenstein Gotha, Schlossplatz 1, 99867 Gotha, Germany. Christian Foth [christian.foth@gmx.net ], Université de Fribourg, Department of Geosciences, Chemin du Musée 6, 1700 Fribourg, Switzerland. Wolf-Dieter Heinrich [ wolf-dieter.heinrich@ mfn.berlin ] and Daniela Schwarz [ Daniela.Schwarz@mfn.berlin], Museum für Naturkunde, Leibniz-Institut für Evolutions- und Biodiversitätsforschung, Invalidenstraße 43, 10115 Berlin, Germany. Robert Bussert [ r.bussert@ tu-berlin.de], Technische Universität Berlin, Institut 
für Angewandte Geowissenschaften, Ernst-Reuter-Platz 1, 10587 Berlin, Germany.

This is an open-access article distributed under the terms of the Creative Commons Attribution License (for details please see creativecommons.org), which permits unrestricted use, distribution, and reproduction in any medium, provided the original author and source are credited.

Fof Full text $(76,490.8 \mathrm{kB})$ ।

For Supplementary file $(192.3 \mathrm{kB})$ 